\title{
GÉNERO E LIDERANÇA NA ESCOLA: DA FEMINIZAÇÃO DA PROFISSÃO DOCENTE AO DESEMPENHO DE CARGOS DE TOPO*
}

\author{
Mafalda Jacques Couto ${ }^{\dagger}$ \\ Paulo Almeida Pereira
}

\begin{abstract}
Resumo: A discriminação social da mulher, ao longo de séculos, ainda hoje ecoa nas sociedades contemporâneas. A alteração do estatuto da mulher, agora com acesso à educação e ao emprego, não bastou para findar a construção de pressupostos de desigualdade social entre homens e mulheres. Embora o princípio de igualdade esteja legalmente estabelecido, as mulheres continuam subrepresentadas nas posições de tomada de decisões. O fenómeno ganha maior significado quando consideramos profissões altamente feminizadas, como é o caso da profissão docente. À semelhança do que ocorre na esfera doméstica, a mulher acaba por desempenhar um papel secundário, contrastando com o protagonismo do homem.

$O$ trabalho de investigação desenvolvido pretende conhecer algumas das representações e conceções que os docentes têm do género e qual a sua influência na eleição dos Conselhos Executivos, órgãos colegiais eleitos pelos membros da comunidade educativa. $O$ enfoque segundo a condição social da mulher, percorrendo a trajetória histórica da relação da mulher com a família e o trabalho, permitiu uma visão geral da forma como os domínios público $e$ privado interferem no acesso das mulheres a cargos de gestão das escolas. Num espaço que se diz, e que se quer, democrático, é pertinente que se percebam, pois, quais os fatores que perpetuam a hierarquização social entre homens e mulheres.

A nossa abordagem incidiu sobre as dimensões da problemática em contexto escolar, nomeadamente a organização, o género e a liderança, com as quais construímos o quadro teórico que sustentou a
\end{abstract}

\footnotetext{
* Este artigo é adaptado de uma dissertação de Mestrado em Administração e Organização Escolar, apresentada no Centro Regional das Beiras da Universidade Católica Portuguesa, em 2011.

$\dagger$ Mestre em Administração e Organização Escolar, Centro Regional das Beiras, Universidade Católica Portuguesa. E-mail: mafaldajacquescouto@ua.pt

* Prof. Auxiliar - Departamento de Economia, Gestão e Ciências Sociais - Pólo de Viseu do Centro Regional das Beiras da Universidade Católica Portuguesa. E-mail: ppereira@crb.ucp.pt
} 
investigação. $O$ estudo realizado junto dos docentes socorreu-se de uma metodologia quantitativa e qualitativa, através da qual procurámos compreender o modo como os professores percecionam o género e até que ponto este é preponderante na escolha de quem está à frente das escolas.

Palavras-chave: Educação, Liderança, Género.

\begin{abstract}
Social discrimination against women, carried out along centuries, still echoes today in modern societies. Changes in the social status of women, who now have access to education and employment, have not been enough to put an end to the construction of assumptions of social inequality between men and women. Although the principle of equality is legally established, women are still subrepresented in posts where decisions are to be taken. The phenomenon reaches a greater meaning when we consider jobs highly feminized, as it is the case of teaching. As well as it happens in the domestic sphere, the woman ends up by having a secondary role, in contrast with the man's protagonism.

The research work that has been developed intends to know some of the representations and conceptions that teachers have about gender and how this influences the election of School Direction Boards, which are the school organs elected by members of the educational community. The approach based on the social condition of women, going through the historical course of women's relationship with family and work, has allowed a general view about the way public and private areas interfere in the access of women to management jobs at school. In an area that is said, and people wish it to be, democratic, it is relevant that we understand the factors that perpetuate the social hierarchy between men and women.

Our approach was focused on the dimensions of this set of questions in school context, namely organization, gender and leadership, with which we have drawn the theoretical frame that has supported the research. The study was carried out with teachers under a qualitative and quantitative methodology. Through this methodology we tried to understand the way teachers perceive gender and to what extent gender is preponderant in the choice of those who are at the frontline in school management.
\end{abstract}

Keywords: Education, Leadership, Gender. 


\section{PAPEL DA MULHER NO SEIO FAMILIAR E NA ESCOLA}

O papel desempenhado por homens e mulheres no seio familiar é distinto e tem vindo a sofrer uma evolução. O trabalho no lar e o trabalho profissional assumem diferentes graus de importância consoante o género considerado. Com efeito, "a mulher dispõe de mecanismos de autoafirmação diferentes dos do homem. Por um lado, o trabalho no lar dá-lhe uma justificação e reconhecimento social. Se, para além disso, tem trabalho profissional, encontra-se numa situação de predomínio dentro do seu sexo. Para o homem é diferente. A sua autoestima e o seu prestígio dependem do que conseguiu fazer na sua profissão, e da sua capacidade para ocupar os cargos de maior responsabilidade e remuneração económica" (Vila, 1988: 82 cit. in Bernardino, 1997: 86-87).

A este facto junta-se aquele de existir uma geração de mulheres que se subjugou perante os homens, contribuindo para "a esperada submissão à casa e à família" (Vieira e Relvas, 2003: 95). Se antes de ingressarem no mercado de trabalho as mulheres tinham a seu cargo a responsabilidade de cuidar da casa e dos filhos, esse facto manteve-se após as mulheres invadirem o mercado laboral. Prevalece a tradição de que "o espaço privado é o espaço da mulher e o espaço público é o espaço do homem" (idem: 83).

Para Araújo (2000), os conceitos de esfera privada e esfera pública estão envoltos em complexidade e tensões, o que está relacionado com a ideologia de "duas esferas separadas" (Araújo, 2000: 114). Constituindose como domínios especializados no que concerne a objetivos, processos, experiências e sentimentos, desde as sociedades do século XIX que ambas as esferas gozam de estatutos diferentes, encontrando-se a esfera privada (ou doméstica) subordinada à esfera pública.

Segundo Grumet (1988), "em muitos aspetos, as estruturas temporais do ensino assemelham-se às rotinas da domesticidade. Fluidos e ubíquos, o trabalho doméstico e as crianças exigiram que as mulheres aceitassem padrões de trabalho e tempo que não têm fronteiras" (Grumet, 1988: 86 cit. in Vieira e Relvas, 2003:95). As mulheres passaram a ter uma jornada dupla de trabalho e particularmente "as professoras têm, um dia 'triplo' de trabalho. Ensinam todo o dia, fazem a maior parte do trabalho doméstico (incluindo tratar dos filhos), e fazem mais trabalho da escola" (Spencer, 1986: 13 cit. in Vieira e Relvas, 2003: 96). Neste sentido, o exercício da docência apresentava-se como uma profissão talhada para as mulheres, conduzindo à feminização daquela profissão. Por um lado, a 
flexibilidade horária permitia que o cuidado do lar e dos filhos não fosse descurado. Por outro lado, a mulher exercia fora de casa uma função que não lhe era alheia: o cuidado de crianças.

\section{LIDERANÇA NAS ORGANIZAÇÕES ESCOLARES}

As diferentes abordagens do conceito de liderança permitem-nos concluir que este dependerá da época e da aproximação escolhidas, sendo muitas as definições que lhe estão associadas. Uma possível definição para liderança pode ser aquela que a considera como "o comportamento que permite e ajuda terceiros a alcançarem objectivos predefinidos" (Whitaker, 2000: 88). A liderança é um fator fundamental no seio das organizações na medida em que existe uma "relação causal entre o factor liderança e os demais factores organizacionais" (Alves, 1999: 38). Com efeito, "a eficiência nas organizações depende da activação da liderança adequada, quando e sempre que necessário" (Whitaker, 2000: 89). Assim sendo, a escola não é exceção à regra de que "qualquer organização que não conte com uma liderança eficiente vive em apuros" (Fiedler e Chemers, 1981: 1). Na diversa literatura sobre a qualidade escolar, frequentemente se aponta para a importância que a liderança assume no desenvolvimento qualitativo da escola. $\mathrm{O}$ aumento de trabalhos na área da liderança escolar está intimamente ligado à crescente valorização que este fenómeno tem vindo a adquirir enquanto fator gerador de qualidade na educação (Bolívar, 2003; Sergiovanni, 1984, 2004).

A adaptação das teorias de liderança ao contexto escolar tem conduzido a que vários autores identifiquem a liderança transformacional como aquela que mais se adequa à realidade escolar (Bernal Agudo, 2000; Bass ,1985; Alvarez 1998; Bolívar, 2003). Partilhando a opinião de Burns (1978), Rocha (2000) refere que "nas organizações educativas dotadas de autonomia, a liderança deve ser mais "transformacional" do que "transacional" (Rocha, 2000: 113). Parafraseando Caldwell e Spinks (1992), a autora refere que a primeira implica a capacidade de envolver os outros num compromisso de mudança, ao passo que a preocupação da segunda é manter o status quo (Rocha, 2000: 113).

Segundo Andrews (2005), a revitalização da escola e o potencial dos professores para desempenhar novas formas de liderança nas escolas requerem uma nova imagem da profissão docente. A investigadora concluiu que existe uma relação de sinergia entre os líderes intermédios e 
os líderes de topo. Na sua opinião, ambos trabalham de forma sustentada na construção de uma escola melhor, o que constitui a liderança paralela.

Apoiando-se em Null (1996), Glanz (2003) opta por definir as características dos líderes educativos defendendo que, no contexto escolar, existem tipos naturais de liderança baseados em qualidades primárias e qualidades secundárias que suportam o comportamento do líder e aos quais estão associadas as virtudes coragem, imparcialidade, empatia, capacidade de julgar, entusiasmo, humildade e imaginação (Glanz, 2003: 15-17).

\section{EMERGÊNCIA DA LIDERANÇA FEMININA}

O recente aparecimento do estudo da liderança feminina deve-se à constatação de que os líderes não são grandes heróis do sexo masculino (Senge, 1990; Costa, 2000). Estudos e investigações apontam no sentido de que "as mulheres adoptam, muitas vezes, um estilo de liderança diferente do que é geralmente adoptado pelos homens nas mesmas circunstâncias" (Teixeira, 1998: 155-156). A propósito da descrição de características de mulheres líderes, Shakeshaft (1989) realça que as mulheres líderes apresentam um perfil notoriamente diferente da imagem tradicional dos homens líderes. Também Krüger (1996) advoga que a variável género tem efeitos significativos na atuação do líder. Desta forma, o género parece condicionar o estilo de liderança praticado. Segundo Teixeira (1998), as mulheres tendem a adotar um estilo mais democrático, encorajando a participação e partilhando o poder, a informação e o desenvolvimento dos subordinados, ao passo que os homens tendem a seguir um estilo de comando e mais controlador. Assim, o desempenho da mulher enquanto líder é baseado no seu carisma, competência, contacto e capacidade de relacionamento para influenciar o comportamento dos subordinados. Apesar disso, esta tendência mais democrática da liderança declina quando a mulher se encontra num meio de tarefas associadas a homens.

Para Cubillo (1999), o facto de homens e mulheres possuírem diferentes abordagens e estilos de liderança encontra-se bem documentado. Segundo a autora, as mulheres identificam-se com um estilo de liderança consultivo, colaborativo, colegial, comunicativo e de maior cuidado do que o estilo de liderança praticado por homens que ocupam posições similares de autoridade. Assim, o estilo de liderança feminino é visto como de transformação e delegação de poderes, em 
oposição ao mero exercício do poder. Para além disso, aos homens associa-se uma maior competitividade.

A associação da liderança ao género masculino é uma velha questão. Com efeito, "o paradigma literário, histórico, político, sociológico, psicológico de referência e de definição dos líderes é um paradigma masculino" (Rocha, 2000: 115). Apoiando-se em Schein (1994) e Hall (1996), Cubillo (1999) refere que existe uma constante associação entre gestão e masculinidade, acrescentando que frequentemente se associam à liderança atributos e comportamentos ditos masculinos, tais como a competitividade, o dinamismo, o poder e a agressividade. Com efeito, nas teorias sobre liderança e nos estudos relativos a escolas eficazes existem poucas referências à variável género. A autora acrescenta que os modelos em que se baseiam as características de líderes eficazes são estereotipadamente androcêntricos (Cubillo, 1999: 547). Esta posição é partilhada por Rocha (2000) que acredita que as conceções baseadas em diferentes critérios de racionalidade, subjacentes à maior parte dos estudos organizacionais, dificultam o estudo e a análise da liderança organizacional feminina no campo educacional uma vez uma "as mulheres são caracterizadas, ao contrário dos homens, como sendo essencialmente emotivas" (Rocha, 2000: 115). Seguindo Morgan (1986), a autora identifica a ética masculina como sendo "a ética predominante nas organizações" (Rocha, 2000: 112) e considera que as organizações, tal como os homens, são encorajadas a seguir uma linha racional, analítica, estratégica, orientada nas decisões, implacável e agressiva.

Apoiando-se em Ferrario (1994), Rocha (2000) salienta que embora as evidências mostrem que existem poucas diferenças de personalidade entre homens e mulheres, existe a crença comum de que as mulheres não possuem os traços de personalidade necessários para se revelarem gestoras bem sucedidas e para agirem enquanto líderes. A ideologia do maternalismo e o processo burocrático da gestão foram fatores que contribuíram para que as mulheres se dedicassem à docência, deixando para os homens os cargos de direção e de gestão (Shakeshaft, 1989; Rocha: 1998). A atribuição de diferentes graus de importância à gestão e à lecionação, social e organizacionalmente, conduziu a que alguns autores percecionassem a docência como uma profissão que não possibilita efetuar uma carreira profissional (Shakeshaft, 1989; Adkison, 1981).

Porém, o facto do maioritário desempenho de cargos de liderança por parte de homens ao longo da história não significa que estes sejam mais aptos para o desempenho de papéis de liderança (Teixeira, 1998) ou que o 
seu estilo de liderança seja melhor (Cubillo, 1999). Segundo Teixeira (1998), as características para o desempenho de uma boa liderança encontram-se presentes tanto em homens como em mulheres podendo estas, eventualmente, revelar uma maior aptidão em situações e tarefas que envolvam a capacidade de negociação, dado que são menos competitivas do que os homens.

Socorrendo-se de Gray (1993), Cubillo (1999) alude à identificação do paradigma feminino como sendo de cuidado e o paradigma masculino como sendo defensivo/agressivo, sendo que nenhum deles é mutuamente exclusivo. A autora alude ainda aos estudos sobre escolas de excelência de Beare et al (1993), que lhes permitiram concluir que quer as qualidades estereotipadas como femininas quer as qualidades estereotipadas como masculinas são importantes na liderança.

Revisitando vários autores, Cubillo (1999) apresenta em síntese três explicações para a sub-representação das mulheres nos cargos de liderança escolar, constituindo-se barreiras às mulheres que ambicionam aceder a este tipo de posto:

i) O efeito da socialização e construção de estereótipos relativos às mulheres faz com que estas sejam vistas como vítimas que precisam de ser ressocializadas de forma a se "encaixarem" no mundo masculino (Shakeshaft, 1989). Existe a noção de que os homens na liderança são a norma e que as mulheres nos mesmos cargos são um desvio a essa norma. Alguma literatura coloca as mulheres num modelo deficitário, tomando por certo que as destrezas que desenvolveram para a gestão não as tornam aptas para o sistema educacional em que trabalham (Gold, 1996). As barreiras organizacionais e sociais impedem que as mulheres reconheçam ou realizem as suas ambições no que toca ao exercício de cargos de liderança, o que se confunde com umas falta de intenção da sua parte (Shakeshaft, 1989). Existe uma antipatia com o conceito masculino de gestão que não atrai as mulheres pois não querem fazer parte de uma cultura que veem como de promoção.

ii) A liderança escolar está declaradamente encoberta de discriminação sexual. Os homens mostram-se relutantes em abandonar os seus postos de poder e, portanto, de forma consciente ou inconsciente, continuam a desvalorizar os contributos das mulheres. Hall (1996) manifesta preocupação quanto aos processos de seleção 
de docentes para cargos de liderança que podem ainda assentar em mitos hostis para as mulheres professoras.

iii) A existência de barreiras internas na organização, tais como a baixa autoestima e a falta de confiança, resultantes das posições de poder e privilégios masculinos. Acker e Feuerverger (1996) afirmam que o sentimento de marginalidade e vulnerabilidade das mulheres não é um sentimento que se possa mudar facilmente. Os autores concluem que a ansiedade decorrente desta luta por uma coexistência verdadeiramente igualitária parece não ser produzida individual mas socialmente (Cubillo, 1999: 549-550).

\section{LIDERANÇA FEMININA EM CONTEXTO EDUCATIVO}

Coleman (2005) refere que, a nível internacional, a profissão docente tende a ser numericamente dominada pelas mulheres mas que, na maioria dos países, essa proporção não encontra correspondência com o exercício de cargos de liderança escolar. Para a autora, numa sociedade pluralista, esta realidade levanta questões que se prendem com a justiça social e com a natureza da liderança educacional. As investigações sobre liderança feminina em contexto educativo são realizadas um pouco por todo o mundo, o que nos permite obter uma visão panorâmica do que se passa relativamente a este fenómeno em diferentes países.

Na Austrália, Weppler (1996), após entrevistar professores, supervisores e diretores, conclui, entre outros, que:

i) Existem mais homens em fim de carreira do que mulheres devido a estas terem menos tempo de serviço, facto que se deve a licenças para se dedicarem à família;

ii) As mulheres diretoras são em média mais velhas que os seus colegas diretores;

iii) As atitudes positivas no desempenho do cargo diretivo devem-se prioritariamente a mulheres;

iv) As mulheres são diretoras de escolas de pequenas dimensões, enquanto os homens são diretores de escolas com mais alunos.

No Reino Unido, Cubillo (1999), após estudar um grupo de candidatos à obtenção de qualificação profissional para exercício de cargos de 
liderança escolar, conclui que:Existem claras diferenças de género no que se refere à capacidade de treino para cargos de liderança escolar;

i) A perspetiva androcêntrica de liderança parece predominar, com consequências negativas para as mulheres que aspiram a posições de gestão escolar;

ii) $\mathrm{O}$ estudo destaca as diferentes abordagens à liderança adotadas por homens e mulheres: por um lado, não houve lugar a um estilo de ouvir e de consideração; por outro, aparentemente as mulheres acham ameaçadora a abordagem competitiva e agressiva dos homens (Cubillo, 1999: 554).

iii) Preocupadas com a forma como eram percecionadas no grupo, as mulheres do estudo não demonstraram vontade em dominar o grupo, sendo movidas mais pelo desejo de desenvolvimento pessoal do que pela pura ambição. A sua falta de confiança foi evidente.

Na Suécia, Persson (2002), após entrevistar alguns elementos de cargos diretivos, conclui que:

i) Entre os diretores existe uma associação entre masculinidade e exercício de lideranças de topo;

ii) Os diretores masculinos identificam-se como intuitivos e preocupados com as relações pessoais, características identificadas como femininas. Por seu lado as mulheres assumem algumas posições tipicamente masculinas. Parece, portanto, que as características da liderança exercida não dependem do género do diretor;

iii) Existe equidade entre os géneros, isto é, homens e mulheres apontam as mesmas dificuldades no acesso a cargos diretivos (Persson, 2002: 83-85).

Nos Estados Unidos da América, Herndon (2002), após inquirir diretores de escolas públicas, a fim de inferir se as práticas de liderança se encontravam relacionadas com o género, conclui que:

i) Não se registaram diferenças entre os dois géneros nas práticas relativas a desafiar, permitir e incentivar;

ii) As mulheres revelam mais aptidão nas práticas relativas aos grupos inspirar e modelar; 
iii) $\mathrm{O}$ número de anos como diretor não está relacionado com nenhuma das cinco práticas de liderança;

iv) As práticas de liderança do grupo desafiar e inspirar estão significativamente relacionadas com o número de anos de serviço como professor.

Em Espanha, Díez et al (2003: 6) concluíram que existe um grande número de professoras, mas são poucas as que exercem cargos de direção. Os autores reportam-se a dados estatísticos decorrentes da investigação de Gairín e Villa (1999), realizada no seu país e que, tendo como objeto de estudo equipas de direção, permitiu concluir que:

i) Os cargos de gestão são desempenhados essencialmente por homens;

ii) Quanto mais elevado é o nível de ensino, menor é a percentagem de mulheres a exercer cargos de direção;

iii) $\mathrm{Na}$ escola pública, a percentagem de mulheres em cargos de direção de escolas com ensino primário é superior à percentagem observada em escolas com ensino secundário;

iv) $\mathrm{Na}$ escola privada, a percentagem de mulheres em cargos de direção de escolas com ensino primário é inferior à percentagem observada em escolas públicas e muito inferior à percentagem observada em escolas com ensino secundário;

v) As mulheres acedem a cargos de direção quando não há homens que os queiram (Gairín e Villa, 1999: 62-63).

No entender dos investigadores existem sete razões que justificam estes factos:

i) Não existe costume social de ver mulheres em cargos de liderança;

ii) As conceções de direção e liderança encontram-se ligadas a um enfoque hierárquico e individualista;

iii) Os homens sentem mais necessidade de conquista pessoal pelo poder;

iv) Existem expectativas sobre ser um homem a desempenhar cargos de liderança;

v) Não há modelos de identificação de mulheres no poder;

vi) A convicção de que já não há discriminação;

vii) A fraca autoestima (Díez et al, 2003: 7-14). 
Em Inglaterra, Coleman (2005) realizou um estudo que foca o impacto do género nas condições do docente se tornar e manter Diretor em escolas secundárias. Na sua opinião, estas áreas raramente são exploradas nos estudos de liderança educacional, onde o género tende a ser um fator de fundo. Assim, a autora lista o seguinte conjunto de vivências relatadas por docentes do género feminino que em alguma altura tentaram o acesso a cargos de liderança escolar:

i) Discriminação nas nomeações;

ii) Preferência inata para nomeações do sexo masculino;

iii) Impacto das responsabilidades domésticas nas nomeações das mulheres;

iv) Aparência pessoal;

v) Confiança e carreira (Coleman, 2005, 6-10).

Abordando as questões de acesso à liderança escolar e trazendo para primeiro plano o fator género, a autora conclui que:

i) As questões de igualdade de género estão ainda presentes pelo menos em metade das mulheres que percecionam discriminação no seu processo de nomeação e no trabalho com colegas e pares;

ii) A autora considera dramático o facto de $70 \%$ das mulheres do estudo se sentirem constrangidas pelas expectativas que os outros têm quanto à prova da sua capacidade enquanto líderes. Na sua opinião, o discurso da liderança tem sido e continua a ser masculino;

iii) Uma das razões porque as mulheres não são favorecidas como Diretoras é o estereótipo de que as mulheres líderes são brandas, indecisas e não se adequam às exigências de um papel duro que requer qualidades masculinas como determinação, assertividade e domínio (Coleman, 2005: 16-18).

A autora refere-se ainda ao estudo de Cubillo e Brown (2003: 285) que, contemplando mulheres oriundas de nove países muito diferentes, lhes permitiu concluir que as mulheres identificaram o apoio paternal, o apoio dos pares, a autoestima e a confiança como influências positivas para o exercício de cargos de liderança, ao passo que as culturas tradicionalmente patriarcais e o evidente domínio masculino da gestão foram identificadas como barreiras a esse mesmo exercício. 
Considerando estas investigações, provenientes de diferentes países com distintas culturas, não passa despercebida a complementaridade e a convergência dos resultados. O facto de investigações recentes revelarem que o ensino é predominantemente desempenhado por mulheres e concluírem, simultaneamente, que estas se encontram minoritariamente representadas no que concerne ao desempenho de papéis de liderança de topo (Riley, 1994) torna necessário "repensar a conceptualização da gestão e da liderança no âmbito das organizações educativas" (Rocha, 2000: 115).

Os constrangimentos com que se deparam as mulheres no exercício da liderança estão relacionados com uma separação social dos indivíduos baseada no seu sexo, resultantes duma hierarquia sexual em que o homem se sobrepõe à mulher (Shakeshaft, 1989; Rocha, 2000).

A literatura que suporta a abordagem deste assunto nunca foi revista ou discutida à luz das questões de género, sendo possível identificar um caráter androcêntrico em conceptualizações e métodos utilizados (Shakeshaft \& Hanson, 1986), bem como uma visão de natureza androcêntrica (Ortiz e Marshall, 1988: 151) que é base de estudos teóricos e trabalhos de pesquisa realizados sobre liderança.

Uma vez que existe a prática de ver e moldar a realidade segundo uma lente masculina (Shakeshaft, 1989a: 325), é necessário que ocorra uma mudança de paradigma para que se possa entender a liderança feminina em toda a sua plenitude (idem). Segundo Shakeshaft (1989a), esta mudança na pesquisa sobre as mulheres deve assentar em seis níveis considerados essenciais para refletir a sua realidade:

i) Ausência de mulheres documentadas;

ii) Procura de mulheres que sejam ou tenham sido administradoras;

iii) As mulheres enquanto prejudicadas ou subordinadas;

iv) Estudar as mulheres nos seus próprios termos;

v) As mulheres como um desafio para a teoria;

vi) Transformação da teoria (Shakeshaft, 1989a: 327).

$\mathrm{Na}$ opinião de Rocha (2000), na organização estabelece-se uma diferenciação assimétrica entre os estilos de liderança feminina e masculina e, indubitavelmente, as mulheres são preteridas em relação aos homens no que toca às questões educativas que envolvam lideranças de topo. Apesar do lugar que a mulher tem vindo a conquistar na sociedade em geral, parece que ainda se mantém à margem da liderança escolar pois 
a gestão educacional é concebida de forma a excluir as mulheres (Riley, 1994; Rocha, 2000). Neste sentido, Coleman (1994) enfatiza a necessidade das mudanças demográficas, ocorridas na escola e na sociedade, se refletirem apropriadamente na liderança escolar.

\section{ESTUDO EMPÍRICO: PERCEÇÕES SOBRE GÉNERO E LIDERANÇA}

\subsection{Metodologia e contextualização do estudo.}

Desenvolveu-se um estudo empírico, em que procurámos analisar as conceções e representações do género no seio da classe docente.

Apontámos como objetivo principal relacionar o género com o exercício de cargos de liderança de topo, com o intuito de perceber se o género do docente, à partida, condiciona a sua possibilidade de exercer um cargo de gestão de uma escola, nomeadamente se o docente pertencer ao género feminino.

A presente pesquisa, com caráter de estudo exploratório, opta por um modelo interpretativo para compreender, com maior rigor e profundidade possíveis, a influência do género no desempenho de cargos de liderança de topo das escolas, numa profissão marcadamente vincada pela presença de mulheres.

O nosso estudo desenvolveu-se junto de professores de escolas secundárias com $3^{\circ}$ ciclo do ensino básico e agrupamentos de escolas do distrito da Guarda, num total de seis estabelecimentos de ensino. A questão de partida desta investigação foi a seguinte:

Numa sociedade onde ainda prevalece a discriminação social da mulher, e sendo a profissão docente maioritariamente desempenhada por mulheres, mais do que o estilo de liderança praticado, o género condiciona a eleição do líder de topo?

O problema da investigação delimitado e os conceitos teóricos que constituíram o suporte da investigação conduziram à formulação de um corpo de hipóteses, cujos resultados serão analisados de seguida. Nos testes de hipóteses, foram utilizados os testes do Qui-quadrado e de Mann-Whitney.

Tendo em conta as características do estudo, a amostra foi selecionada pelo método de amostragem por conveniência, tendo sido escolhidas seis escolas pertencentes ao distrito da Guarda, onde foi aplicado o questionário (nos meses de maio/junho e de setembro/outubro de 2007), com o propósito de conhecer as representações que os professores têm do 
género e da liderança exercida pelo órgão de gestão da sua escola. Abarcando quarenta questões, trinta e sete de resposta fechada e três de resposta aberta, este instrumento dividiu-se em duas partes: i) identificação do docente e ii) questões sobre género e liderança. Foram distribuídos 360 questionários, 60 por escola participante no estudo, tendo sido recolhidos 186 questionários, o que corresponde a uma taxa de retorno de $52 \%$. O erro associado ao estudo, para um nível de confiança de $95 \%$, é de $5 \%$.

\subsection{Apresentação, análise e discussão de resultados}

\section{Caracterização da amostra}

O questionário foi respondido por 133 mulheres e 53 homens, pelo que a representatividade das mulheres no estudo é de $71,5 \%$. Relativamente à idade dos inquiridos, cerca de metade dos inquiridos $(51,6 \%)$ tem idade inferior ou igual a 40 anos. A habilitação literária predominante é a Licenciatura (80,1\%), seguindo-se o Mestrado (7\%), o Bacharelato $(4,8 \%)$, Especialização $(3,2 \%)$ e o Doutoramento $(0,5 \%)$. Quanto ao estado civil, 127 são casados $(68,3 \%)$ e 7 vivem em união de facto $(3,8 \%)$, pelo que $72,1 \%$ dos inquiridos mantêm uma relação conjugal. $\mathrm{Na}$ amostra existem ainda 38 professores solteiros $(20,4 \%), 10$ divorciados $(5,4 \%), 3$ viúvos $(1,6 \%)$ e 1 professor separado $(0,5 \%)$.

No que concerne ao nível de ensino, o ensino do $3^{\circ}$ ciclo e secundário é o que tem uma maior representatividade $(74,2 \%)$, seguido do $2 .^{\circ}$ ciclo $(17,2 \%)$, em oposição ao $1 .^{\circ}$ ciclo $(5,9 \%)$ e ao ensino pré-escolar $(2,7 \%)$. Para esta distribuição terá contribuído o facto de o inquérito ter sido distribuído na escola sede dos agrupamentos de escolas.

Relativamente ao vínculo profissional, 119 docentes (64\%) são Professores do Quadro de Nomeação Definitiva, 17,2\% são Professores de Quadro de Zona Pedagógica e 18,8\% são professores contratados.

\section{Tarefas Domésticas}

Começando pela análise da questão sobre se recebem ajuda do cônjuge nas tarefas domésticas, o género masculino recebe ajuda do seu cônjuge em $84,6 \%$ dos casos, enquanto que o feminino recebe ajuda do cônjuge em $38,1 \%$ dos casos. Estas percentagens evidenciam a divisão de papéis existente no seio familiar, verificando-se a hipótese "Receber ajuda do cônjuge para as tarefas domésticas depende do género do docente" (Qui-quadrado: $\mathrm{p}<0,001$ ).

Particularizando a confeção das refeições enquanto tarefa doméstica, $82 \%$ no género feminino confecionam as refeições com regularidade, o 
mesmo sucede com apenas $24,5 \%$ no género masculino, o que valida a hipótese "A confeção das refeições depende do género do docente" ( $p<$ $0,001)$.

Relativamente ao cuidado de familiares dependentes pelo próprio, no género feminino as respostas afirmativas correspondem a 87,2\% ao passo que no género masculino são 53,3\%: na maioria dos casos, cabe à mulher o acompanhamento de familiares dependentes, o que confirma a hipótese "O cuidado de familiares dependentes por parte do próprio docente depende do seu género" $(\mathrm{p}=0,007)$.

Dada a importância que a existência de filhos tem no desempenho profissional das mulheres, quisemos saber a cargo de quem ficam os filhos dos docentes inquiridos. Note-se que $37 \%$ dos respondentes não têm filhos, $30 \%$ têm um filho, $29 \%$ têm dois filhos e $4 \%$ têm três filhos ou quatro filhos. Para os docentes com filhos, o elemento do género masculino cuida dos filhos em horário laboral em 7,7\% dos casos, enquanto que o feminino o faz em 14,3\% dos casos, o que não permitiu validar a hipótese "Em horário laboral, o cuidado dos filhos pelo cônjuge do docente depende do seu género" $(\mathrm{p}=0,274)$. Os reduzidos valores observados devem-se ao facto de que o cuidado dos filhos neste horário fica a cargo de familiares, do infantário, ou de outros.

O cuidado de filhos doentes é realizado pelo próprio em $61,5 \%$ dos casos no género feminino e em $40 \%$ no masculino, pelo que as mulheres cuidam mais frequentemente dos filhos doentes do que os homens, verificando-se a hipótese " $\mathrm{O}$ cuidado de filhos doentes pelo próprio docente depende do seu género" ( $\mathrm{p}=0,033)$.

O cuidado de filhos doentes pelo cônjuge do docente inquirido é referido em $18,2 \%$ no género feminino e $80 \%$ no género masculino. Assim, o cônjuge mulher cuida dos filhos doentes com uma frequência consideravelmente superior à do cônjuge homem, o que confirma a hipótese "O cuidado de filhos doentes pelo cônjuge do docente depende do seu género" ( $p<0,001)$.

As duas últimas análises corroboram que de facto é a mulher a maior responsável pelo cuidado dos filhos em caso de doença, tanto no papel de docente inquirida como no papel de cônjuge de um docente inquirido. 


\section{Desempenho de Cargos de Liderança Escolar Intermédia}

No que concerne ao desempenho de cargos de liderança intermédia por parte dos docentes, as respostas são afirmativas para $57,9 \%$ das mulheres e $65,4 \%$ dos homens. No entanto, esta pequena diferença não confirma a hipótese "O exercício de cargos de liderança escolar intermédia depende do género do docente" $(\mathrm{p}=0,350)$.

Especificamente, quanto ao desempenho dos cargos de Presidente da Assembleia, Coordenador de Departamento, Coordenador de Diretores de Turma, não se verificam diferenças significativas entre os géneros. Quanto ao cargo de Diretor de Turma, ele é referido por 53,2\% no género feminino e $27,8 \%$ no género masculino, sendo mais desempenhado por mulheres, verificando-se a hipótese " $\mathrm{O}$ desempenho do cargo de Diretor de Turma depende do género do docente" $(\mathrm{p}=0,011)$.

\section{Presidente do Conselho Executivo}

Indagados quanto à sua preferência relativamente ao género do Presidente do Conselho Executivo, 10,3\% dos docentes referiram que preferiam um homem, 5,4\% uma mulher e $84,3 \%$ responderam que lhes era indiferente. A opção homem foi escolhida por $4,5 \%$ no género feminino e $25 \%$ no masculino e a opção mulher foi escolhida por $6,8 \%$ no género feminino e 1,9\% no masculino, validando a hipótese "A preferência quanto ao género do Presidente do Conselho Executivo depende do género do docente" $(p<0,001)$, existindo maior preferência pelo mesmo género.

Outro aspeto estudado refere-se à pretensão do docente integrar uma lista para concorrer ao Conselho Executivo da sua escola, desempenhando funções no órgão de gestão, sendo as respostas afirmativas de $17,2 \%$ para o género feminino e de $36,7 \%$ para o masculino: os docentes homens consideram mais vir a integrar um órgão de gestão escolar, o que valida a hipótese "A pretensão do docente concorrer ao Conselho Executivo depende do seu género" $(\mathrm{p}=0,005)$.

Os motivos para não querer concorrer ao Conselho Executivo são a falta de interesse (41,1\% nas mulheres e $34,3 \%$ nos homens), a falta de tempo (40,0\% nas mulheres e $28,6 \%$ nos homens), não ter perfil para ocupar cargos de gestão (31,6\% das mulheres e $28,6 \%$ dos homens), não ser do quadro da escola (24,6\% nas mulheres e $17,1 \%$ nos homens). Como outros motivos menos referidos são apontados residir longe da escola onde exerce funções (mais pelos homens) e preferir exercer a atividade letiva em vez de cargos de gestão (mais pelas mulheres). Menos referidos ainda são a remuneração pouco compensatória associada ao desempenho de cargos no órgão de gestão escolar, a falta de experiência, 
a falta de apoio e a falta de oportunidade. Nenhum dos motivos apresenta diferenças significativas entre os géneros, não se verificando a hipótese "Os motivos indicados pelo docente que justificam uma resposta negativa quanto à pretensão de concorrer ao Conselho Executivo dependem do seu género".

Os docentes que manifestaram a sua vontade em concorrer ao órgão de gestão invocaram sete motivos: melhorar a escola foi referido por $13,8 \%$ das mulheres e $31,4 \%$ dos homens, sendo as diferenças significativas $(\mathrm{p}=0,041)$, sentindo-se os homens mais responsáveis do que as mulheres no que toca ao seu contributo para melhorar a escola. $\mathrm{O}$ interesse pela gestão é indicado por $13,8 \%$ e $28,6 \%$ no masculino; a aquisição de novas experiências é referida por $11,1 \%$ no género feminino e a $17,1 \%$ no masculino; a aquisição de novos conhecimentos é referida por $8,1 \%$ das mulheres e $14,3 \%$ dos homens; são ainda indicados, com menor frequência, o facto de os docentes integrantes do órgão de gestão terem uma maior flexibilidade horária, a possibilidade de aproximação à residência e a curiosidade; todos estes motivos não apresentam diferenças significativas entre os géneros. Assim sendo, a hipótese "Os motivos indicados pelo docente que justificam uma resposta positiva quanto à sua pretensão de concorrer ao Conselho Executivo dependem do seu género", apenas se verifica para o motivo melhorar a escola.

\section{Desempenho de Cargos de Gestão}

$\mathrm{Na}$ amostra, 18,9\% das mulheres revelaram já ter pertencido ao órgão de gestão no passado, enquanto, no caso dos homens, essa percentagem é de $28,3 \%$, dados que não validam a hipótese "O desempenho passado de cargos de gestão escolar depende do género do docente" $(\mathrm{p}=0,162)$. Relativamente ao tipo de cargos de gestão desempenhados pelos docentes, o cargo de Presidente foi desempenhado por 11,5\% das mulheres e 37,5\% dos homens, diferenças significativas que suportam a hipótese "O desempenho passado do cargo de Presidente depende do género do docente" $(\mathrm{p}=0,046)$, o cargo de Vice-presidente foi desempenhado por $65,4 \%$ no género feminino e $66,7 \%$ no masculino, o de Assessor foi desempenhado por $34,6 \%$ das mulheres e $46,7 \%$ dos homens, cargos para os quais não se verificam se hipóteses " $O$ desempenho passado do cargo de Vice-presidente e de Assessor depende do género do docente".

Quanto à situação presente, o desempenho de algum cargo de gestão escolar é de $9 \%$ para as mulheres e de $22,6 \%$ para os homens, confirmando a hipótese "O desempenho atual de cargos de gestão escolar 
depende do género do docente" $(\mathrm{p}=0,012)$. Especificando, o cargo de Presidente é exercido por $8,3 \%$ das mulheres e $41,7 \%$ no caso dos homens, o de Vice-presidente é desempenhado por $66,7 \%$ no género feminino e $50 \%$ no masculino, o de Assessor é desempenhado por $25 \%$ no género feminino e $8,3 \%$ no masculino. As diferenças não são estatisticamente significativas para nenhum dos cargos, não confirmando a hipótese "O desempenho atual do cargo de Assessor depende do género do docente".

\section{Importância de Qualidades do Líder}

Com o objetivo de determinarmos se as qualidades do líder eram percecionadas de igual forma por docentes de géneros diferentes, foram apresentadas, aos professores, catorze qualidades para que estes lhes atribuíssem um determinado grau de importância (numa escala de Likert com cinco categorias): Preocupado, Intuitivo, Não competitivo, Subjetivo, Seguidor/ cumpridor de regras, Avaliador, Objetivo, Criativo, Consciente das diferenças individuais, Tolerante, Informal, Conformista, Disciplinado e Formal. Aquelas que obtiveram maior média para o grau de importância foram Consciente das diferenças individuais $(4,28)$, Objetivo $(4,23)$ e Disciplinado $(4,12)$, enquanto as qualidades a que os docentes atribuíram menor importância foram Formal $(2,46)$, Subjetivo $(2,27)$ e Conformista $(2,04)$.

Procedendo a uma análise segundo o género, na amostra, verificam-se pequenas diferenças entre os géneros, com as mulheres a darem mais importância que os homens a Seguidor/Cumpridor de regras, Consciente das diferenças individuais, Tolerante e Disciplinado, acontecendo o inverso com Preocupado, Intuitivo, Subjetivo, Informal, Conformista e Formal. No entanto, nenhuma das diferenças observadas são estatisticamente significantes, de acordo com os resultados do teste de Mann-Whitney, não se verificando a hipótese "O grau de importância que o docente atribui a uma determinada qualidade do líder escolar depende do seu género". 


\subsection{Entrevistas}

Foram ainda realizadas entrevistas a duas mulheres ocupantes do cargo de Presidentes dos Conselhos Executivos, com dezoito questões, distribuídas por cinco blocos: Candidatura ao cargo de Presidente do Conselho Executivo; Incentivos à candidatura em função do género; Interferência do desempenho do cargo com a vida familiar; Perceções quanto ao género e estilos de liderança; Expectativas futuras; cujos resultados de análise de conteúdos não se apresentam aqui, mas contribuíram para a discussão apresentada de seguida.

\section{DISCUSSÃO DOS RESULTADOS}

À semelhança dos dados estatísticos decorrentes das investigações de Gairín e Villa (1999) e de Díez et al (2003), também na Guarda se verifica que os cargos de direção escolar são desempenhados essencialmente por homens. Na senda de alguns motivos conducentes a esta realidade, o nosso estudo veio mostrar que a fraca representatividade das mulheres em órgãos de gestão escolar mais não é do que uma consequência da realidade social da mulher. As conclusões prévias do nosso estudo encontram-se ordenadas em três grupos.

\subsection{Tarefas domésticas e cuidados dos filhos}

Dividida entre o trabalho, as tarefas domésticas e os filhos, numa jornada múltipla de trabalho (Spencer, 1986; Simón, 2000; Díez et al, 2003; Vieira e Relvas, 2003), a mulher debate-se com uma constante falta de tempo (Simón, 2000) que a afasta dos cargos de gestão escolar de topo. A desigual dedicação de homens e mulheres ao espaço privado (Moreno, 2000) faz com que a mulher coloque as tarefas domésticas à frente das profissionais (Díez et al, 2003), o que se traduz na fragmentação da presença feminina no mercado de trabalho (Moreno, 2000). Confirmando estes factos, as entrevistadas do nosso estudo são de opinião que o cargo de Presidente do Conselho Executivo não conta com mais mulheres por uma questão cultural que se prende com o papel socialmente atribuído à mulher: ser mãe e dona de casa, cuidar dos filhos e apoiar o marido, são encaradas como tarefas femininas que, pelo tempo que exigem, condicionam o acesso das mulheres aos cargos de gestão escolar. Neste sentido, as responsabilidades familiares condicionam as mulheres a nível profissional (Díez et al, 2003). 
O nosso estudo revelou que embora a ajuda nas tarefas domésticas seja independente do género do docente, existe uma relação de dependência entre a origem dessa ajuda e o género do docente. Com efeito, a ajuda recebida depende do género do docente quando esta é oriunda do cônjuge. Esta realidade assume um significado maior quando se concretiza o caso da confeção de refeições.

Mas o papel social da mulher não se limita ao desempenho de tarefas domésticas, estendendo-se ao cuidado dos filhos e de familiares dependentes, caso existam, numa clara submissão da mulher à casa e à família (Vieira e Relvas, 2003).

Também o cuidado de familiares dependentes está relacionado com o género do docente no caso de ser prestado pelo próprio docente ou pelo seu cônjuge. Além disso, pressupondo-se que cabe à mulher o cuidado de filhos doentes (Cavaco, 1993), o nosso estudo mostrou que, em caso de doença dos descendentes do docente, existe uma relação de dependência entre o género do docente e o cuidado prestado pelo próprio docente e pelo seu cônjuge.

Aquando a realização das entrevistas, pudemos auscultar que as próprias mulheres se julgam as únicas responsáveis capazes de desempenhar tarefas relacionadas com o lar e com os filhos, sendo este um aspeto cultural profundamente enraizado. Assim, quando as mulheres aceitam cargos de gestão escolar sentem que relegaram a sua família, e as obrigações que lhe são inerentes, para um segundo plano. Nestas circunstâncias, as mulheres experimentam uma sensação de culpa decorrente do abandono do lar (Díez et al, 2003) e algumas, com receio que a sua vida profissional prejudique a sua vida familiar, acabam por abandonar os cargos de gestão, em benefício dos homens. Além disso, na opinião das nossas entrevistadas, existe a falta de hábito de ver mulheres no cargo de gestão de topo, pelo que não existem modelos de identificação de mulheres no poder (idem).

Em suma, dado que nenhuma política é capaz de mudar a vida privada, os seus valores e os seus comportamentos (Moreno, 2000), e uma vez que os modelos familiares se reproduzem no espaço público (idem), todo o suporte legal promotor de igualdade entre homens e mulheres de nada serve se não for implementada a democracia no seio familiar. Uma das nossas entrevistadas remata o seu pensamento acrescentando que caso as tarefas desempenhadas atualmente pelas mulheres fossem da responsabilidade dos homens, então seriam as 
mulheres que estariam representadas em maior número nos cargos de gestão escolar.

\subsection{Desempenho do cargo de Gestão Escolar e género}

Não existindo costume social de ver mulheres em cargos de liderança (Díez et al, 2003), no nosso estudo concluímos que o desempenho de cargos de liderança escolar intermédia é independente do género do docente. Porém, a preferência quanto ao género do Presidente do Conselho Executivo, cargo de liderança escolar de topo, é dependente do género. Esta relação mantém-se para os cargos de Presidente de Assembleia, Coordenador de Departamento, Coordenador dos Diretores de Turma e outros. A contrariar esta tendência temos o cargo de Diretor de Turma.

As nossas entrevistadas consideraram que o género é uma vantagem para aceder a cargos de gestão escolar. Estas intervenientes reafirmaram que o desempenho deste tipo de cargos está posto de parte pelas mulheres devido à falta de tempo, limitadora das suas escolhas profissionais.

A pretensão do docente em concorrer ao Conselho Executivo apresenta uma relação de dependência com o género, o mesmo ocorrendo com a indicação de alguns dos motivos que justificam a sua escolha.

No que respeita às nossas entrevistadas, ambas referiram que se tornaram Presidentes do Conselho Executivo da sua escola por uma questão de oportunidade e acaso, dado que eram vice-presidentes dos Conselhos Executivos anteriores e os Presidentes que as antecederam não pretendiam continuar a desempenhar esse cargo. Por outro lado, as docentes não tiveram qualquer lista oponente quando integraram pela primeira vez o órgão de gestão, o que aponta no sentido de as mulheres acederem a cargos de direção quando não há homens que os queiram (Gairín e Villa, 1999; Díez et al., 2003). 


\subsection{Estilos de Liderança e género}

Quanto às palavras-chave que descrevem o estilo de liderança do docente no órgão de gestão, o nosso estudo provou que as palavras-chave oriundas de grupos relativos a relações interpessoais, colegialidade, exercício do poder e cumprimento de regras são independentes do género do docente. Diferindo nas suas opiniões quanto a este assunto, uma das nossas entrevistadas considerou que o género do Presidente condiciona a sua tomada de decisões, ao passo que, para a outra entrevistada, em vez do género é a experiência pessoal que determina o estilo de liderança.

A abordagem destas questões, relativas aos valores que o líder escolar tenta promover e o estilo de liderança que pratica, permitiram-nos identificar conceções confluentes para a conclusão de que as características da liderança não dependem do género do líder escolar (Persson, 2002).

A associação entre masculinidade e exercício de lideranças de topo (idem), bem como o facto de homens e mulheres apontarem as mesmas dificuldades no acesso a cargos diretivos (ibidem) não se encontram pois relacionados com o género.

Analisadas que estão todas estas dimensões, resta-nos retomar a hipótese geral do nosso estudo cuja complexidade nos obrigou a percorrer diferentes vertentes de análise. Considerando todas as conclusões referidas ao longo do trabalho, concluímos que homens e mulheres têm caminhos diferentes a percorrer quando pretendem aceder a cargos de gestão escolar. Com efeito, enquanto que os homens estão plenamente livres para exercer o cargo, as mulheres ponderam constantemente sobre as implicações do seu exercício na vida familiar, o que condiciona as suas escolhas a este nível. Neste sentido, parece-nos lógico validar a hipótese de que "As funções sociais atribuídas às mulheres, como a maternidade, a gestão doméstica e a educação dos filhos, a par da perceção social do binómio género/liderança, condicionam o acesso das docentes a cargos de liderança de topo". Com efeito, Coleman (2005) retrata esta realidade na perfeição, socorrendo-se de uma metáfora muito curiosa extraída de um artigo relacionado com os problemas profissionais de mulheres na China:

"Women and men are like two athletes running on the same track. But the men run free while the women balance children in one hand and kitchenware in the other. And even if the encumbered women run as fast as the men, people then criticize them for not running gracefully" (Fu Jun, 1995 cit. in Coleman, 2005: 4). 


\section{CONCLUSÃO}

Apesar de toda uma constelação de estudos efetuados no âmbito da Administração e Gestão Escolar, a análise das desigualdades entre homens e mulheres continua a encontrar terreno fértil e faz sentido num contexto em que os cargos de liderança escolar de topo são desempenhados quase exclusivamente por homens, não obstante as mulheres constituírem o maior contingente na profissão docente.

Não podendo, porque o teor deste trabalho não o permite, estudar as relações de género com a amplitude que a problemática possibilitaria, foi nossa preocupação conhecer e aferir causas plurais para a realidade descrita. Visando um contributo para a desmontagem da construção do papel social da mulher, enquanto elemento inibidor da sua participação em cargos de gestão escolar de topo, abordámos conceções e representações dos docentes quanto ao desempenho deste tipo de cargos e ao género de quem os ocupa. $\mathrm{O}$ alargamento do nosso universo de análise a duas entrevistadas com experiência na gestão escolar veio colmatar o nosso estudo. Nesta fase, parece-nos pois oportuno apresentar uma síntese de linhas mais expressivas desenvolvidas no trabalho, não sob um ponto de vista parcelar, mas procurando dar uma visão global do mesmo.

Ao longo da história, as mulheres foram silenciadas e a sua presença sempre assumiu um papel secundário. Ainda que se apregoassem os princípios de Liberdade, Igualdade e Fraternidade, a mulher não teve direito à cidadania, à palavra e à participação no espaço público (Rocha, 2005). Sendo um facto recente, a igualdade jurídica entre homens e mulheres nem sempre encontra correspondência com as práticas sociais, existindo muitas formas de diferenciação assimétrica nas funções exercidas pelos homens e pelas mulheres.

Antes de afirmar que as mulheres não ocupam cargos de poder porque não querem, ou porque têm outras prioridades (Díez et al, 2003), importa referir que as organizações, nomeadamente as escolas, reproduzem os papéis sociais de género existentes na sociedade, que muitas vezes relegam a mulher para segundo plano.

As políticas instauradas pelo Estado Novo, assentes na ideologia do maternalismo, em muito contribuíram para a diferenciação e hierarquização de papéis na escola. Ao passo que as mulheres eram consideradas, por natureza e por socialização, aptas para o ensino, os homens viam reconhecidas as suas aptidões para o exercício de cargos de gestão. As medidas políticas vigentes direcionavam as mulheres para o 
exercício de determinadas profissões, como a docência, às quais era atribuído um menor prestígio social. Neste sentido, ao invés de se constituir um meio para o reconhecimento da importância do papel social da mulher, a feminização do ensino é vista como um dos fatores que contribuiu para a degradação do estatuto socioprofissional dos professores (Braga da Cruz, 1988).

A atribuição assimétrica de papéis a homens e mulheres está profundamente enraizada, quer a nível social quer a nível cultural, de tal forma que "o alcance da justiça social é por muitos e muitas considerado como um alvo utópico devido, precisamente, às grandes dificuldades e aos constrangimentos que advêm dos modelos políticos, sociais e organizacionais que institucionalizaram a diferenciação assimétrica entre os homens e as mulheres em diversos contextos de acção" (Rocha, 2005: 456).

Não raras vezes a desigualdade dos papéis socialmente atribuídos a homens e mulheres tem a sua génese no espaço familiar. Nesta dimensão de análise, as tarefas encontram-se estipuladas em função do género, ainda que subliminarmente, numa clara associação entre a natureza da tarefa e a pessoa a quem se destina. Embora exista a convicção de que já não há discriminação (Díez et al, 2003), a igualdade entre pessoas de géneros diferentes, tanto nas organizações como na família, nem sempre se verifica.

Neste quadro assim pintado, não é de estranhar que muitas mulheres, nomeadamente professoras, se alienem do desempenho de cargos de liderança escolar de topo. Por um lado, o tempo das suas vidas está totalmente preenchido com a sua profissão, o cuidado do lar e o cuidado dos filhos. Por outro lado, muitas mulheres não se sentem suficientemente apoiadas para vir a desempenhar um cargo daquele tipo. Com efeito, "a ordem masculina faz com que as práticas sociais femininas sejam vistas como suportes da mesma, como elementos culturais que a reproduzem" (Rocha, 2005: 457).

Não tendo ficado estabelecida qualquer relação entre os valores promovidos pelo líder escolar de topo ou os estilos de liderança que pratica e o seu género, estamos em crer que a mudança da realidade observada passa sobretudo pela redefinição dos conceitos de democracia, de igualdade, de cidadania, de cultura, de esfera pública e privada. Estes são os vetores de transformação e mudança que permitirão valorizar o papel social e cultural da mulher na família, na organização e na sociedade em geral, alavancando uma nova realidade. Embora a 
igualdade entre géneros esteja legalmente salvaguardada há mais de trinta anos, só a criação de condições para a afirmação igualitária das mulheres nos diferentes espaços possibilitará um acesso paritário das mulheres aos cargos de liderança escolar de topo, desmistificando conceções de direção e liderança ligadas a um enfoque hierárquico e individualista (Díez et al, 2003) característico dos homens. Com efeito, "não basta adoptar um modelo de cidadania universalista, é necessário criar as condições para o seu exercício, sob risco de os efeitos objectivos perverterem os efeitos desejados e se ampliarem as desigualdades" (Ferreira, 1999: 224).

Para finalizar, gostaríamos de acrescentar que para se operarem mudanças no acesso à gestão escolar por parte das mulheres é impreterível a existência de uma vontade feminina neste sentido. Com efeito, ainda que se fomente uma maior democracia familiar e que se liberte a mulher em termos de tempo, isso de nada servirá se ela continuar a alhear-se da gestão escolar meramente por uma questão de cariz cultural. Também nós acreditamos que “ (...) a cultura não é a pessoa mas está com a pessoa até ao mais íntimo do seu ser e agir existencial" (Gameiro, 1984:36) e que "o indivíduo não é somente o produto da sua cultura, mas também a constrói, a reconstrói, a recria, em função das problemáticas e das estratégias diversificadas e num contexto marcado pela diversidade e pela pluralidade" (Ramos, 2001: 165). Assim, a mulher não pode permitir que os aspetos culturais lhe continuem a toldar a visão. $\mathrm{O}$ seu contributo para uma mudança cultural que lhe faculte uma maior participação é um predicado para uma nova realidade. De facto, "se é certo que não se pode prescindir das histórias e culturas recebidas, também parece certo que uma das tarefas mais difíceis que tem de enfrentar quem se sinta excluído do poder de decidir será a de refutar a história da sua opressão e transformá-la na base de uma acção presente e futura" (Rocha, 2005: 461). Para tal, tenha-se como exemplo Carolina Beatriz Ângelo, natural da Guarda, que se bateu pela emancipação das mulheres ... há cem anos. 


\section{BIBLIOGRAFIA}

ACKER, S. \& FEUERVERGER, G. (1996). "Doing Good and Feeling Bad: The Work of Women University Teachers". Cambridge Journal of Education, 26, pp. 401-422.

ADKISON, J. (1981). "Women in School Administration: A Review of the Research". Review of Educational Research, 51 (3), pp. 311-343.

ALVAREZ, F. (1998). El liderazgo de la calidad total. Madrid: Escuela Española.

ALVES, J. (1999). Organização, Gestão e Projecto Educativo das Escolas. Porto: Edições ASA.

ANDREWS, D. (2005). "Ordinary People in the Act of doing Extraordinary things: Teacher as leaders in school revitalisation". REICE. Revista Electrónica Iberoamericana sobre Calidad, Eficacia y Cambio en Educación, 3 (1), pp. 240.

ARAÚJO, H. (2000). As Pioneiras na Educação. As Professoras Primárias na Viragem do Século: Contextos, Percursos e Experiências. 1870-1933. Lisboa: Instituto de Inovação Educacional.

BASS, B. (1985). Leadership and performances beyond expectation. New York: Free Press.

BEARE, H., CALDWELL, B. \& MILIKAN, R. (1993). "Leadership". In PREEDY, M. (Ed.). Managing the Effective School. London: Paul Chapman, pp. 141-162.

BERNAL AGUDO, J. (2000) "Liderar el Cambio: El Liderazgo Transformacional". Anuario de Pedagogía, 2, pp. 197-230.

BERNARDINO, M. (1997). Feminização do Ensino Secundário: $\left(7^{\circ}\right.$ $12^{\circ}$ anos de escolaridade). Implicações no Estatuto Socioprofissional $e$ Burnout. Dissertação de Mestrado. Coimbra: Faculdade de Psicologia e Cências da Educação da Universidade de Coimbra.

BOLÍVAR, A. (2003). Como Melhorar as Escolas. Porto: Edições ASA.

BRAGA DA CRUZ, M., DIAS, A. SANCHES, J., RUIVO, J. \& TAVARES J. (1988). "A Situação do Professor em Portugal". Análise Social, 24, pp. 1187-1293.

BURNS, J. (1978). Leadership. New York: Harper \& Row.

CALDWELL, B. \& SPINKS, J. (1992). Leading the Self-Managing School. London: Falmer Press.

CAVACO, M. (1993). Ser Professor em Portugal. Lisboa: Editorial Teorema.

COLEMAN, M. (1994). "Women in Educational Management". In BUSH, T. \& WEST-BURNHAM, J. (Eds.). The Principles of Educational Management. Harlow: Longman, pp. 177-197. 
COLEMAN, M. (2005). "Gender and Secondary School Leadership". International Studies in Educational Administration, 33, pp. 3-20.

COSTA, J. (2000). "Liderança nas organizações: revisitando teorias organizacionais num olhar cruzado sobre as escolas". In COSTA, J., MENDES, A. \& VENTURA, A. (Org) Liderança e Estratégia nas Organizações Escolares. Aveiro: Universidade de Aveiro, pp. 1533.

CUBILLO. 1. (1999). "Gender and Leadership in the National Professional Qualification for Head Teachers: an opportunity lost?". Journal of In-service Education, 25 (3), pp. 545-556.

CUBILLO, 1. \& BROWN, M. (2003). "Women into Educational Leadership and Management: International Differences?". Journal of Educational Administration, 41 (3), pp. 278-291.

DÍEZ GUTIÉRREZ, E., VALLE FLÓREZ, R., TERRÓN BAÑUELOS, E. \& CENTENO SUÁREZ, B. (2003). "El Liderazgo Femenino y su Ejercicio en las Organizaciones Educativas". Revista Iberoamericana de Educación, ISSN:1681-5653

FERRARIO, M. (1994). "Women as Managerial Leaders". In DAVIDSON, M. \& BURKE, R. (Eds.). Women in Management. Current Research Issues. London: Paul Chapman Publishing Ltd., pp. 110-125.

FERREIRA, V. (1999). "Os Paradoxos da Situação das Mulheres em Portugal”. Revista Crítica de Ciências Sociais, (52/53), pp. 199-227.

FIEDLER, F. \& CHEMERS, M. (1981). Liderança \& Administração Eficaz. São Paulo: Livraria Pioneira Editora.

GAIRÍN, J. \& VILLA, A. (1999). Los Equipos Directivos de los Centros Docentes. Análisis de su Funcionamento. Bilbao: Universidad de Deusto.

GAMEIRO, Aires (1984). Emigrantes: psicologia social: conflitos e desafios culturais. Lisboa: Centro do Livro Brasileiro e Obra Católica Portuguesa de Migrações.

GLANZ, J. (2003). À Descoberta do seu estilo de liderança: Um guia para educadores e professores. Porto: Edições ASA.

GOLD, A. (1996). "Women into Educational Management". European Journal of Education, 31, pp. 419-433.

GRAY, H. (1993). "Gender Issues in Management Training”. In OZGA, J. (Ed.). Women in Educational Management. Bukingham: Open University Press, pp. 106-115.

GRUMET, M. (1988). Bitter Milk: Women and Teaching. Massachusetts: University of Massachusetts Press.

HALL, V. (1996). Dancing on the Ceiling: a Study of Women Managers in Education. London: Paul Chapman. 
HERNDON, J. (2002). Gender Differences in High School Principal's Leadership Styles. Doctoral Dissertation. Califórnia: School of Education, University of the Pacific.

KRÜGER, M. (1996). "Gender Issues in School Headship: quality versus power?”. European Journal of Education, 31, pp. 447-461.

MORENO, E. (2000). "La Transmisión de Modelos Sexistas en la Escuela". In SANTOS GUERRA, M. (Coord.). El harén pedagógico. Perspectiva de género en la organización escolar. Barcelona: Graó, pp. 11-32.

MORGAN, G. (1986). Images of Organizations. London: Sage Publications.

NULL, G. (1996). Who are you, really? Understanding your life's energy. New York: Carrol \& Graf.

ORTIZ, F. \& MARSHALL, C. (1988). "Women in Educational Administration". In BOYAN, N. (Coord.). Handbook of Research on Educational Administration. A Project of the American Educational Research Association. New York/London: Longman, pp. 123-141.

PERSSON, A. (2002). Gender equal leadership? Gender, organization and leadership in the educational system. Tese de estudante. Suécia: Institutionen för tematisk utbildning och forskning, Linköping Universitet.

RAMOS, N. (2001). "Comunicação, cultura e interculturalidade: para uma comunicação intercultural”. Revista Portuguesa de Pedagogia, 35 (2), pp. 155-178.

RILEY, K. (1994). Quality and Equality. Promoting Opportunities in Schools. London: British Library.

ROCHA, C. (1998). "Democracia e Participação. A Feminização da Gestão Escolar e a Realização da Escola Democrática". Revista Educação, 7 (2), pp. 29-40.

ROCHA, C. (2000). "Perspectivas organizacionais sobre a liderança feminina em contexto educativo". In COSTA, J., MENDES, A. \& VENTURA, A. (Org) Liderança e Estratégia nas Organizações Escolares. Aveiro: Universidade de Aveiro, pp. 109-118.

ROCHA, C. (2005). Educação, Género e Poder. Uma Abordagem Política, Sociológica e Organizacional. Tese de Doutoramento. Braga: Instituto de Educação e Psicologia, Universidade do Minho.

SCHEIN, V. (1994). "Managerial Sex Typing: a persistent and pervasive barrier to women's opportunities" In DAVIDSON, M. \& BURKE, R. (Eds). Women in Management: Current Research Issues. London: Paul Chapman, pp. 41-52.

SENGE, P. (1990). The Fifth Discipline. The Art and the Practice of the Learning Organization. London: Century Business. 
SERGIOVANNI, T. (1984). "Leadership and Excellence in School". Educational Leadership, 41, pp. 4-13.

SERGIOVANNI, T. (2004). Novos Caminhos para a Liderança Escolar. Porto: Edições ASA.

SHAKESHAFT, C. (1989). Women in Educational Administration. London: Sage Publications.

SHAKESHAFT, C. (1989a). "The Gender Gap in Research in Educational Administration". Educational Administration Quaterly, 25 (4), pp. 324-337.

SHAKESHAFT, C. \& HANSON, M. (1986). "Androcentric Bias". Educational Administration Quaterly, 22 (1), pp. 68-92.

SIMÓN, M. (2000). "Tiempos y Espacios para la Coeducación". In SANTOS GUERRA, M. (Coord.). El harén pedagógico. Perspectiva de género en la organización escolar. Barcelona: Graó, pp. 33-51.

SPENCER, D. (1986). Contemporany Women Teachers. Balancing School and Home. New York: Longman.

TEIXEIRA, S. (1998). Gestão das Organizações. Lisboa: McGraw-Hill.

VIEIRA, C. \& RELVAS, A. (2003). A(s) Vida(s) do Professor. Escola e Família. Coimbra: Quarteto Editora.

VILA, J. (1988). La Crisis de la Función Docente. Valencia: Promolibro.

WEPPLER, M. (1996). Teachers, Supervisors, Principals: Gender Interplays. Annual Conference of the Australian Association for Research in Education, Hobart, November 1995, Australia.

WHITAKER, P. (2000). Gerir a Mudança nas Escolas. Porto: Edições ASA. 